\title{
DECENTRALIZED EMISSION STANDARDS WITH TAX COMPETITION
}

By

Jeffrey Petchey

School of Economics and Finance

Curtin University

Curtin 笽

University of Technology

ISSN: 1835-9450

09.04 


\title{
Decentralized Emission Standards with Tax Competition
}

\author{
Jeffrey D Petchey
}

\begin{abstract}
We consider a game between jurisdictions within a national economy. Capital migrates between jurisdictions to satisfy an equal return condition. The total supply of capital to the economy is a non-decreasing function of the national return. This allows us to cater for the case where capital has some home bias and jurisdictions have an incentive to engage in tax competition and set non-zero capital taxes in equilibrium. We then show that this competition does not distort emissions standards and that decentralized provision of environmental policy is locally efficient. Thus, we find no evidence of a race to the bottom or top in emissions standards as a result of tax competition.
\end{abstract}

Key words: emissions, standards, capital tax, local public goods, decentralization.

JEL Codes: Q50, Q56, Q58, H70, H77, H23, H41.

\footnotetext{
${ }^{1}$ Correspondence: Email: Jeff.Petchey@cbs.curtin.edu.au Mailing address: School of Economics and Finance, Curtin University, GPO Box U1987, Perth, WA, 6845, Australia. Phone: 618 92667408. Fax: 61 892663026.
} 


\section{The issue}

Jurisdictions in decentralized economies, such as federations, may choose inefficient environmental policies in order to attract mobile firms. Models that obtain this result assume that environmental inputs are un-priced and jurisdiction specific. Each jurisdiction therefore generates environmental rents captured by mobile firms as profit. Firms migrate to the jurisdiction with the highest profit and allocate themselves between jurisdictions to equate per firm profits. Hence, firm location decisions are sensitive to any jurisdictional policies, including emissions control, that affect the size of the profits (rents) available. In order to attract mobile firms jurisdictions are willing to lower emissions standards below the level consistent with efficiency. While this is a public good under provision result, in the parlance of the environmental economics literature it is termed a 'race to the bottom'2. The focus therefore is on models where firm mobility in response to jurisdictional environmental rents, captured by firms as profits, is the main source of inter jurisdictional competition and hence distortion to environmental policy.

The capital market structure adopted in these models has an exogenously fixed quantity of capital that migrates within the national economy to equate the return (price) in each jurisdiction with an exogenously given return. This is a particular capital market structure where the national capital market is fully open to the world market and the exogenously given return is the world return. We know, as is shown by Oates and Schwab (1988), that the optimal tax on mobile capital in this case is zero. In other words, states do not find it in their interests to engage in tax competition with this type of capital market structure. Models that adopt such assumptions about the capital market do not capture the interaction between tax competition and environmental policy.

In this paper, we develop a more general market for mobile capital that allows capital to have 'home bias'. This allows for the possibility of partial capital market integration where the domestic return to capital is endogenous. Jurisdictions have market power over capital and find it in their interests to set non-zero capital taxes, thus engaging in tax competition. This also allows us to capture perfect capital market integration where jurisdictions are competitive in the market for capital, set zero capital taxes, and

\footnotetext{
2 For example, see Kunce and Shogren (2002, 2005, 2007, 2008). Exceptions to this result include Oates and Schwab (1988) who find that decentralized environmental policy is efficient, and Wellisch (1996) who finds that jurisdictions over provide standards - a race to the top.
} 
there is no tax competition. This more encompassing capital market structure allows us to focus on the impact of tax competition on the choice of decentralized environmental policy.

To achieve our aims we develop a simultaneous move game between two jurisdictions (players) that are part of a national economy. Perfect capital mobility within the domestic economy ensures equality of capital returns across jurisdictions and the total supply of capital is a non-decreasing function of this economy-wide return. Each jurisdiction has two continuous pure strategies, direct choice of emission standards, and a per unit tax on mobile capital. Players hold Nash conjectures with regard to other players' strategy choices. Jurisdictions choose their emissions and the tax to maximize the welfare of immobile households, and take into account the capital location decisions made in response to their choices. There is therefore tax competition between jurisdictions, and competition over emission standards - hence we think of this as an emissions-tax competition game.

We examine the necessary conditions for emissions standards and the capital tax that must hold in any equilibrium to the game. This leads to a general result that holds regardless of the degree of capital market integration, namely, that jurisdictions will set their capital taxes to exactly offset the impact of tax competition on the choice of emissions. The result is that any equilibrium to the game is efficient in the sense that the choice of emissions by each jurisdiction satisfies a locally optimal Samuelson condition in which the marginal cost of emissions is equal to the marginal benefit. Thus, tax competition has no implications for the efficiency of decentralized emission policies. We do argue however that emissions are 'over produced' in equilibrium (standards are too lax) because jurisdictions ignore the negative spillover effect of their emission choice. It is for this reason that we refer to a Nash equilibrium as locally efficient.

The organization of the paper is as follows. Section 2 develops the emissions-tax competition game. This section includes a proposition that presents the main result of the paper regarding the efficiency of a decentralized equilibrium with tax competition. Section 3 examines particular cases where we make special assumptions about the nature of the capital market. We link the discussion to findings in the existing literature. Section 4 concludes while we relegate technical details to the appendix. 


\section{Emissions-Tax Competition Game}

Consider a national economy with just two jurisdictions $j=1,2$ that differ in terms of production technologies and preferences. Each jurisdiction has a single (identical) industry sector producing a numeraire output $y_{j} \geq 0$ with two fixed inputs land $L_{j}$ and labor $H_{j}$ supplied by immobile households and two variable inputs. The first variable input capital $k_{j}$ is mobile across jurisdictions and between the economy and the rest of the world. The second variable input $e_{j}$ is waste emissions treated as a non-purchased input to the production process in jurisdiction $j$. We assume that the government of jurisdiction $j$ sets the total amount of emissions allowable within its borders through direct environmental controls and regulation ${ }^{3}$. Thus, $e_{j}$ is a choice variable for jurisdiction $j$ and is the inverse of environmental standards: higher waste emissions arise from more lax standards.

Jurisdiction $j$ has a fixed supply of firms $G_{j}^{i}$. All firms are identical and assumed to have constant returns to scale. They are identified as $g_{j}^{i}=1, \ldots, G_{j}^{i}$ where $i=1, \ldots, I$. Output of firm $i$ is therefore

$$
y_{j}^{i}=g_{j}\left(\frac{L_{j}}{G_{j}^{i}}, \frac{H_{j}}{G_{j}^{i}}, \frac{k_{j}}{G_{j}^{i}}, \frac{e_{j}}{G_{j}^{i}}\right) .
$$

Total output for jurisdiction $j$ (also exhibiting constant returns) is ${ }^{4}$

$$
y_{j}=f_{j}\left(k_{j}, e_{j}\right)=G_{j} \cdot y_{j}^{i}
$$

The $j$ subscript implies that jurisdictions can have different production technologies even though firms within a jurisdiction are identical. They may also have different endowments of the fixed factors. This is one source of asymmetry in the model.

\footnotetext{
${ }^{3}$ This is as in Oates and Schwab (1988).

${ }^{4}$ For notational convenience land and labor supply are not included explicitly in the analysis from now on since these factors are fixed in supply. With constant returns, total output in jurisdiction $j$ is exhausted by factor payments. This makes the exposition more convenient without changing the qualitative results. Note also that jurisdiction output is a function of the number of firms. In this paper, the number of firms is held fixed and hence not included as an argument of the production function. Finally, the price of the numeraire output is set at one across the federation so $y_{j}$ is also the value of output in jurisdiction $j$ (analogously for $-j$ ).
} 
The partial derivatives $\partial f_{j} / \partial k_{j}, \partial f_{j} / \partial e_{j}, \partial f_{j} / \partial L_{j}$ and $\partial f_{j} / \partial H_{j}$ are the marginal products of capital, emissions, land and labor respectively. Each marginal product is positive and decreasing in own-factor supply and is enhanced by the quantity of the other factors present (inputs are complements). The market for capital in jurisdiction $j$ is perfectly competitive so capital receives a return $\omega_{j}$ equal to its marginal product. Labor and land receive a wage $w_{j}$ and return $\rho_{j}$ (respectively) equal to their marginal products. Therefore, define

$$
\frac{\partial f_{j}}{\partial k_{j}}=\omega_{j}\left(k_{j}, e_{j}\right), \frac{\partial f_{j}}{\partial H_{j}}=w_{j}\left(k_{j}, e_{j}\right), \frac{\partial f_{j}}{\partial L_{j}}=\rho_{j}\left(k_{j}, e_{j}\right) .
$$

The price of land and labor are exogenous from the perspective of the jurisdictions while the price of mobile capital is endogenous (as will be seen below). As noted, we assume that emissions are a non-purchased input to production. The environmental rent generated in jurisdiction $j$ is, therefore,

$$
\frac{\partial f_{j}}{\partial e_{j}} e_{j}
$$

where $\partial f_{j} / \partial e_{j}$ is the marginal product of emissions and $e_{j}$ is the level of emissions in state $j$.

Suppose that jurisdictions have a second instrument, a per unit tax $t_{j}$ on capital. The net return to capital in jurisdiction $j$ is

$$
x_{j}=\omega_{j}\left(k_{j}, e_{j}\right)-t_{j} .
$$

Jurisdictions share a national capital market in which capital moves across borders without restriction to equate the net return

$$
x_{j}=x_{-j}=x
$$

where $x$ is the national net return to capital.

Let $K$ denote the total supply of capital to the national economy. The net return to capital is positive and finite for all $\forall K \in(0, K]$. Capital supply is a monotonically nondecreasing function of the national net return, which by (6) is also the net return in state $j$. Hence, we define 


$$
K=k_{j}+k_{-j}=K\left(x_{j}\right) .
$$

From (7) the capital supply to jurisdiction $-j$ is

$$
k_{-j}=K\left(x_{j}\right)-k_{j} .
$$

The single capital equilibrium condition that must hold for the economy, given that there is free capital mobility between jurisdictions, and that the economy is open to the outside world, is, therefore

$$
\omega_{j}\left(k_{j}, e_{j}\right)-t_{j}=\omega_{-j}\left(K\left(x_{j}\right)-k_{j}, e_{-j}\right)-t_{-j} .
$$

Let each immobile household in jurisdiction $j$ consume a pure private good $X_{j}$. The payoff for a representative immobile household is

$$
P^{j}\left(X_{j},-e\right)
$$

where $e=e_{j}+e_{-j}$ is the aggregate level of emissions in the economy - the sum of individual jurisdiction emission levels. Waste emissions produced by each jurisdiction create a perfect (negative) spillover for households in the other jurisdiction.

The payoff function is continuous, increasing and concave in consumption and decreasing in $e$ (more emissions reduce household payoff). The $j$ subscript on the payoff function implies that preferences for a representative household in jurisdiction $j$ can differ from those for a representative household in $-j$.

By virtue of the assumption that firms have constant returns to scale the value of output in jurisdiction $j$ is equal to the sum of factor payments and the emissions rent, so that $f_{j}\left(k_{j}, e_{j}\right)=\rho_{j} L_{j}+w_{j} H_{j}+\omega_{j} k_{j}+\left(\partial f_{j} / \partial e_{j}\right) e_{j}$. We assume that immobile households collectively own all land and the environment within their respective jurisdictions and that, therefore, land income $\sigma_{j} L_{j}$ and emissions rent $\left(\partial f_{j} / \partial e_{j}\right) e_{j}$ accrue to them as income ${ }^{5}$. Each household also supplies one unit of labor, hence $H_{j}$ is the number of households in jurisdiction $j$ and its labor supply, and $w_{j} H_{j}$ is the wage bill for jurisdiction $j$. This also accrues to households as income. The payment made to capital $\omega_{j} k_{j}$ is the only component of income (output) not collected by households - this accrues to residents outside of the national economy - hence $k_{j}$ is foreign owned capital.

\footnotetext{
${ }^{5}$ Oates and Schwab (1988) also assume that environmental rent accrues to immobile households.
} 
Therefore, household income in jurisdiction $j$ is equal to the economic residual in that jurisdiction ${ }^{6}$

$$
f_{j}\left(k_{j}, e_{j}\right)-\omega_{j} k_{j} .
$$

Governments represent household interests so the jurisdiction $j$ objective is

$$
P_{j}\left(\frac{f_{j}\left(k_{j}, e_{j}\right)-\left(\omega_{j}-t_{j}\right) k_{j}}{H_{j}},-e\right) .
$$

The government chooses its waste emissions and capital tax to maximize (12) taking into account mobile capital location choices made in response to these choices. There are two forms of competition between jurisdictions. First, the mobile capital equilibrium condition implies that a jurisdiction's choice of waste emissions influences the supply of capital within its own boundaries, and hence in the neighboring jurisdiction. Since the welfare of the neighboring jurisdiction is dependent on its capital supply, the jurisdictional emission standards chosen in any particular jurisdiction influences welfare in the other jurisdiction through the capital equilibrium condition. There is therefore 'emission standards' competition between jurisdictions. Second, by the same logic a jurisdiction's choice of tax influences the supply of capital and welfare in neighboring jurisdictions. We also therefore have capital tax competition between jurisdictions, induced by capital mobility and the capital equilibrium condition. This is the same tax competition modeled in the tax competition literature.

We therefore model the problem as an emissions-tax competition game with two jurisdictions playing a simultaneous move game in two continuous and pure strategies represented by the strategy vector $\sigma_{j}=\left(e_{j}, t_{j}\right)$. Nash conjectures describe behavior and hence each jurisdiction makes its strategy choice conditional on the strategy choices of the other player. Further, each player takes into account the impact of its choices on the supply of capital within its own jurisdiction to the extent that such responses affect its

\footnotetext{
${ }^{6}$ Firm profits in jurisdiction $j$ are therefore zero and $\pi_{j}^{i}=\pi_{-j}^{i}=0 \forall i$ holds in equilibrium - firms have no incentive to move between jurisdictions, hence the assumption that the number of firms in jurisdiction $j$, $G_{j}$, is fixed. In some models, including Kunce and Shogren (2005), environmental (emissions) rent accrues to firms as profit, hence $\pi_{j}=\left(\partial f_{j} / \partial e_{j}\right) e_{j}$. Differences in environmental rent (profit) between jurisdictions cause firms to migrate to exploit arbitrage opportunities and equate the per-firm share of rents across jurisdictions. The emphasis is then on how competition between jurisdictions to attract mobile firms seeking jurisdictional rents distorts environmental emissions policy.
} 
own welfare. Jurisdictions face an inherent tension in setting their waste emission standards and capital taxes, namely, they wish to choose their emissions and the tax to achieve some desired supply of capital and hence consumption, which yields positive payoff, but at the same time producing waste emissions reduces their payoff. Managing this trade off to maximize payoff, given feasibility and the available strategy set, is the problem solved by each jurisdiction in the emissions-tax competition game.

We derive in the appendix the necessary condition for emissions in a representative jurisdiction $j$. The condition includes a term that captures how capital supply to a jurisdiction changes in response to greater waste emissions, a term that we call the 'capital supply response' to increased waste emissions. In the appendix, we show from the capital equilibrium condition that the supply of capital to each jurisdiction is an implicit function of the policies of any particular jurisdiction, conditional on neighboring policies. We use this to obtain an expression for the capital supply response to increased emissions. Once substituted into the emissions necessary condition this yields a single equation describing equilibrium choices of emissions in state $j$,

$$
-H_{j} \frac{P_{e}^{j}}{P_{X_{j}}}=\frac{\partial f_{j}}{\partial e_{j}}-\underbrace{t_{j} \frac{\partial \omega_{j}}{\partial e_{j}} \frac{\left(1-K_{x_{j}} \omega_{-j}^{\prime}\right)}{E}-\frac{\partial \omega_{j}}{\partial e_{j}} \frac{k_{j} \omega_{-j}^{\prime}}{E}}_{\text {Tax competiton wedge }} .
$$

Similarly, we derive the tax necessary condition and the capital supply response to a change in the tax that must hold in any equilibrium for the game (see appendix). Using the capital supply response in the tax necessary condition, we obtain one expression describing the optimal capital tax chosen by state $j$ in a Nash equilibrium to the game,

$$
t_{j}^{*}=\frac{-k_{j} \omega_{-j}^{\prime}}{\left(1-K_{x_{j}} \omega_{-j}^{\prime}\right)} \geq 0 .
$$

Hence, for state $j$ we have two equations that must be satisfied in equilibrium, (13) and (14), and two unknowns, emissions and the capital tax. Analogous conditions hold for $-j$.

Now consider the emissions necessary condition more closely. $H_{j} P_{e}^{j} / P_{X_{j}}$ is the marginal rate of substitution between the local public bad, emissions, and consumption $X_{j}$, summed over all identical household in jurisdiction $j$. This is, therefore, the aggregate marginal cost of more emissions in jurisdiction $j$ in terms of reduced payoff for households. Each indifference curve defined between consumption and emissions is 
upward sloping; for a given payoff, households require more consumption if emissions increase. The first term on the right side $\partial f_{j} / \partial e_{j}$ is the marginal product or incremental output from a one-unit increase in emissions (positive) - the marginal benefit of higher emissions. The remaining terms comprise the 'tax competition wedge'; they are present because as emissions increase the jurisdiction must take account of the impact on capital location decisions via the capital equilibrium condition. At first sight therefore, tax competition leads jurisdictions to adopt necessary conditions for emissions in which marginal cost diverges from marginal benefit. This implies that emissions standards are potentially inefficient.

The question we now address is whether the tax competition wedge has any impact within the emission necessary condition, and hence on the efficiency of emission standards, once we take explicit account of the capital tax levied by jurisdictions. We do this in the following proposition, the main result of the paper:

Proposition 1: In a Nash equilibrium to the game jurisdictions choose emissions standards consistent with a locally optimal Samuelson condition.

Proof: Using the expression for the capital tax (14) in the emissions necessary condition (13) and simplifying yields the environmental Samuelson condition

$$
-H_{j} \frac{P_{e}^{j}}{P_{X_{j}}^{j}}=\frac{\partial f_{j}}{\partial e_{j}} .
$$

This expression must be satisfied in any Nash equilibrium to the game and analogously for jurisdiction $-j . / /$

The implication of the proposition is that waste emissions are efficient in any Nash equilibrium with two instruments, emissions and a tax on mobile capital, since the marginal cost of emissions is equal to the marginal benefit in terms of additional output. The capital tax chosen by jurisdiction $j$ exactly offsets the tax competition wedge in the emissions necessary condition and tax competition over mobile capital does not induce jurisdictions to over or under use waste emissions. It is always in their interests to use the capital tax to acquire desired supplies of capital and provide emission standards 
efficiently. We are careful to note however that emissions standards are not efficient from the perspective of the national economy because jurisdictions still ignore the spillover of waste emissions for households in neighboring jurisdictions. Since the spillover is negative any equilibrium in which (15) is satisfied (analogously for $-j$ ) implies over provision of emissions for the national economy, and hence that environmental standards are too low. We emphasize that the source of this over provision of emissions lies with the spillover and not with distortions arising from tax competition.

\section{Particular Case: Perfect Integration}

We now examine the particular case of perfect capital market integration. In this instance, jurisdictions act competitively in the market for capital, set a zero capital tax (and hence pay mobile capital its full marginal product) and do not engage in tax competition. We discuss this special case in the context of other results on the efficiency of decentralized emissions policy found in the environmental economics literature.

To consider this particular case, refer to the appendix and note that the change in total capital supply to the national economy $K_{x_{j}}$ used in the capital supply responses is equal to the underlying supply elasticity $\varepsilon$ multiplied by the stock of capital $K$ divided by the national return to capital (its price) $x_{j}$. Thus, we define $K_{x_{j}}=\varepsilon\left(K / x_{j}\right)$ and note that this allows us to examine three cases. First, as $\varepsilon \rightarrow \infty$ then we have $K_{x_{j}} \rightarrow \infty$. Petchey and Shapiro (2002) show that in this case the national return to capital must approach some given world return if an equilibrium is to exist, that is, $x_{j} \rightarrow \bar{x}_{j}$, where $\bar{x}_{j}$ is the given world return. The national economy also has a given stock of capital, $\bar{K}\left(\bar{x}_{j}\right)$. Second, if $\varepsilon=0$ then $K_{x_{j}}=\varepsilon\left(K / x_{j}\right)=0$ and we have the case where the national capital market is closed from the world market, and capital supply is unresponsive to changes in the local return relative to the world return. Finally, if $0<\varepsilon<\infty$ the national capital market is partly closed (open) to the world capital market and total capital supply responds to changes in the national return relative to the world return.

The equation for the optimal capital tax is now 


$$
t_{j}^{*}=\frac{-k_{j} \omega_{-j}^{\prime}}{\left(1-\varepsilon\left(K / x_{j}\right) \omega_{-j}^{\prime}\right)} .
$$

Note also that $E$, used earlier and defined in the appendix, becomes

$$
E=\omega_{-j}^{\prime}+\omega_{j}^{\prime}\left(1-\varepsilon\left(K / x_{j}\right) \omega_{-j}^{\prime}\right)
$$

We now state the following proposition:

Proposition 2: When $\varepsilon$ is infinite jurisdictions choose a zero capital tax in equilibrium, and emissions are locally efficient.

Proof: From (16) $t_{j}^{*} \rightarrow 0$ as $\varepsilon \rightarrow \infty$ and hence the tax competition wedge in the emissions necessary condition (13) becomes

$$
\frac{\partial \omega_{j}}{\partial e_{j}} \frac{k_{j} \omega_{-j}^{\prime}}{E} .
$$

Since $E \rightarrow 0$ as $\varepsilon \rightarrow \infty$ the tax wedge also approaches zero as epsilon becomes infinite. This in turn means that when epsilon is infinite the emissions necessary condition is equivalent to the locally efficient Samuelson condition, (15).//

Thus, when epsilon is infinite, the capital tax is zero, the supply of capital is $\bar{K}\left(\bar{x}_{j}\right)$, the tax competition wedge disappears and emissions are locally efficient. This result highlights the generality of proposition 1 - it holds regardless of the value of epsilon, and serves to emphasize that when epsilon is infinite the capital tax is zero and emissions are efficient. However, when epsilon is less than infinite the tax is positive and exactly offsets the non-zero tax competition wedge so that emissions are still efficient.

The capital market captured in proposition 2 is the one modeled by Oates and Schwab (1988), and Kunce and Shogren (2005). They assume there is some given economy wide return, a fixed national supply of capital, and that the stock of capital allocates itself across jurisdictions to equate the jurisdictional net return with a given national return ${ }^{7}$. Oates and Schwab have a capital tax and obtain the result that the

\footnotetext{
${ }^{7}$ For example, see equation (2) on page 337 in Oates and Schwab (1988) and equation (2) on page 215 in Kunce and Shogren (2005). In these papers, the given return is denoted as $r$ and is equivalent to our $\bar{x}$.
} 
optimal tax is zero and that environmental policy is efficient - these are the results of proposition 1 for the case where epsilon is infinite. We can now see that this is a particular case where emissions are locally efficient. When epsilon is less than infinite the capital tax is positive and offsets the impact of tax competition on emissions.

Kunce and Shogren (2005) allow for a capital tax but contrary to our results find that the equilibrium tax is non-zero, and that the outcome is inefficient. This is despite them having a perfectly integrated capital market with an exogenous capital return and fixed supply of capital. The difference in results arises because these authors allocate environmental rents to mobile firms rather than immobile households (as here). Consequently, their necessary condition for the optimal capital tax is a function of firm profits $^{8}$. While these profits are positive, the optimal capital tax is non-zero in their model and any equilibrium is inefficient, even though the capital market is fully integrated.

\section{Conclusion}

In this paper we have examined the potential impact of tax competition between jurisdictions on the efficiency of decentralized setting of emissions standards. We have argued that this can best be done using a model that allows for varying degrees of integration of the national capital market with the world capital market. In particular, we have catered for the case where capital has some home bias, and jurisdictions have an incentive to set positive capital taxes in equilibrium and hence engage in tax competition with one another. Interestingly, though there is the potential for such competition to distort emissions policy through a wedge in the necessary condition for emissions, we have shown that jurisdictions will set the capital tax to exactly offset the effect of this wedge. Emissions standards are then provided in a manner consistent with local efficiency and tax competition does not contribute to any race to the bottom or top in emissions standards. We have pointed out however that such standards are still under provided, but this is because of the negative externality between jurisdictions, rather than tax competition. Finally, we have linked the results with findings in other papers in the relevant literature.

\footnotetext{
${ }^{8}$ See equation 25 in Kunce and Shogren (2005). Note that Kunce and Shogren $(2005,2008)$ use a tax on land, rather than a capital tax, to obtain an efficient outcome though still using a model with a perfectly integrated capital market.
} 


\section{$\underline{\text { Appendix }}$}

\section{Emissions Standards Necessary Condition}

We obtain the necessary condition for emissions by differentiating

$$
P_{j}\left(\frac{f_{j}\left(k_{j}, e_{j}\right)-\left(\omega_{j}-t_{j}\right) k_{j}}{H_{j}},-e\right)
$$

with respect to $e_{j}$ conditional on $e_{-j}$ and $t_{-j}$. Note that in (1.1) we add the revenue from the capital tax to the total income of households and allocate it on an equal per capita basis. The necessary condition is

$$
\frac{P_{X_{j}}^{j}}{H_{j}}\left(\frac{d f_{j}}{d e_{j}}+\omega_{j} \frac{\partial k_{j}}{\partial e_{j}}-\left(\omega_{j}^{\prime} \frac{\partial k_{j}}{\partial e_{j}}+\frac{\partial \omega_{j}}{\partial e_{j}}\right) k_{j}-\omega_{j} \frac{\partial k_{j}}{\partial e_{j}}+t_{j} \frac{\partial k_{j}}{\partial e_{j}}\right)-P_{e}^{j}=0 .
$$

Multiplying through by $H_{j} / P_{X_{j}}^{j}$, cancelling terms and rearranging yields,

$$
-H_{j} \frac{P_{e}^{j}}{P_{X_{j}}}=\frac{\partial f_{j}}{\partial e_{j}}-\left(\omega_{j}^{\prime} k_{j}-t_{j}\right) \frac{\partial k_{j}}{\partial e_{j}}-\frac{\partial \omega_{j}}{\partial e_{j}} k_{j} .
$$

This is the necessary condition for emissions standards in state $j$.

\section{Capital Supply Response to Increased Emissions}

Define the strategy vector of jurisdiction $j$ as $\sigma_{j}=\left(t_{j}, e_{j}\right)$ and analogously for $-j$. We now express the capital net return in jurisdiction $j$ as $x_{j}\left(k_{j}, \sigma_{j}\right)$ and the net return in $-j$ as $x_{-j}\left(K\left(x_{j}\right)-k_{j}, \sigma_{-j}\right)$. The capital equilibrium condition becomes

$$
v\left(k_{j}, \sigma_{j}, \sigma_{-j}\right)=x_{j}\left(k_{j}, \sigma_{j}\right)-x_{-j}\left(K\left(x_{j}\right)-k_{j}, \sigma_{-j}\right)=0 .
$$

The net return $x_{j}\left(k_{j}, \sigma_{j}\right)$ is monotonically decreasing in $k_{j} \forall \sigma_{j}$ and $x_{-j}\left(K\left(x_{j}\right)-k_{j}, \sigma_{-j}\right)$ is monotonically decreasing in $k_{j} \forall \sigma_{-j}$. Hence, $v(\cdot)$ is monotonically decreasing in $k_{j}$. Since the jurisdiction $j$ and $-j$ returns $x_{j}\left(k_{j}, \sigma_{j}\right)$ and $x_{-j}\left(K\left(x_{j}\right)-k_{j}, \sigma_{-j}\right)$ are continuous in $k_{j}, v(\cdot)$ is also continuous in $k_{j}$. There exists, 
therefore, a unique $k_{j}$ that satisfies $v\left(k_{j}, \sigma_{j}, \sigma_{-j}\right)=0$ implying the following functional relationship between $k_{j}$ and $\sigma_{j}$, conditional on $\sigma_{-j}$,

$$
k_{j}\left(\sigma_{j} \mid \sigma_{-j}\right)
$$

We therefore derive the capital supply response to a change in emissions by differentiating the capital equilibrium condition with respect to $e_{j}$ for given $e_{-j}$ and $t_{j}$. This yields

$$
\omega_{j}^{\prime} \frac{\partial k_{j}}{\partial e_{j}}+\frac{\partial \omega_{j}}{\partial e_{j}}-\omega_{-j}^{\prime} K_{x_{j}}\left(\omega_{j}^{\prime} \frac{\partial k_{j}}{\partial e_{j}}+\frac{\partial \omega_{j}}{\partial e_{j}}\right)+\omega_{-j}^{\prime} \frac{\partial k_{j}}{\partial e_{j}}=0 .
$$

$K_{x_{j}}=d K / d x_{j}$ is the change in total (national) capital supply as the return to capital in jurisdiction $j$, and hence the national economy, increases by one unit. The sign is zero or positive since $K$ is non-decreasing in $x_{j}$ by assumption. The partial derivatives $\omega_{-j}^{\prime}=\partial^{2} \omega_{-j} / \partial k_{-j}^{2}$ and $\omega_{j}^{\prime}=\partial^{2} \omega_{j} / \partial k_{j}^{2}$ are negative since we have assumed diminishing returns. Collecting up for $\partial k_{j} / \partial e_{j}$ and $\partial \omega_{j} / \partial e_{j}$ equation (2.5) becomes

$$
\frac{\partial k_{j}}{\partial e_{j}}\left(\omega_{-j}^{\prime}+\omega_{j}^{\prime}\left(1-K_{x_{j}} \omega_{-j}^{\prime}\right)\right)+\frac{\partial \omega_{j}}{\partial e_{j}}\left(1-K_{x_{j}} \omega_{-j}^{\prime}\right)=0 .
$$

We present this expression more compactly by defining

$$
E=\omega_{-j}^{\prime}+\omega_{j}^{\prime}\left(1-K_{x_{j}} \omega_{-j}^{\prime}\right) .
$$

Using this (2.4) becomes

$$
\frac{\partial k_{j}}{\partial e_{j}} E+\frac{\partial \omega_{j}}{\partial e_{j}}\left(1-K_{x_{j}} \omega_{-j}^{\prime}\right)=0 .
$$

Multiplying through by $1 / E$ and rearranging the emissions capital supply response is

$$
\frac{\partial k_{j}}{\partial e_{j}}=-\frac{\partial \omega_{j}}{\partial e_{j}} \frac{\left(1-K_{x_{j}} \omega_{-j}^{\prime}\right)}{E}>0
$$

We know that $\omega_{-j}^{\prime}<0$ and $\omega_{j}^{\prime}<0$ since we have assumed diminishing returns, and hence that $E<0$. The implication is that the capital supply response is positive; an increase in emissions attracts more capital to state $j$. 


\section{Capital Tax Necessary Condition}

We find the necessary condition for the capital tax by differentiating (1.1) with respect to $t_{j}$ conditional on $e_{-j}$ and $t_{-j}$ yielding

$$
\frac{P_{X_{j}}^{j}}{H_{j}}\left(\omega_{j} \frac{\partial k_{j}}{\partial t_{j}}-\omega_{j}^{\prime} \frac{\partial k_{j}}{\partial t_{j}} k_{j}-\omega_{j} \frac{\partial k_{j}}{\partial t_{j}}+k_{j}+t_{j} \frac{\partial k_{j}}{\partial t_{j}}\right)=0 .
$$

Multiplying through by $H_{j} / P_{X_{j}}^{j}$, cancelling terms and rearranging yields

$$
\left(\omega_{j}^{\prime} k_{j}-t_{j}\right) \frac{\partial k_{j}}{\partial t_{j}}=k_{j} .
$$

This is the necessary condition for the capital tax in jurisdiction $j$.

\section{Capital Supply Response to a Higher Tax}

We find the capital supply response to a change in the capital tax by differentiating the capital equilibrium condition with respect to $t_{j}$ conditional on $e_{-j}$ and $t_{-j}$. This yields

$$
\omega_{j}^{\prime} \frac{\partial k_{j}}{\partial t_{j}}-1-\omega_{-j}^{\prime}\left(K_{x_{j}}\left(\omega_{j}^{\prime} \frac{\partial k_{j}}{\partial t_{j}}-1\right)-\frac{\partial k_{j}}{\partial t_{j}}\right)=0 .
$$

Collecting up for $\partial k_{j} / \partial t_{j}$ yields

$$
\frac{\partial k_{j}}{\partial t_{j}}\left(\omega_{-j}^{\prime}+\omega_{j}^{\prime}\left(1-K_{x_{j}} \omega_{-j}^{\prime}\right)\right)-\left(1-K_{x_{j}} \omega_{-j}^{\prime}\right)=0 .
$$

Using the definition of $E$ this becomes

$$
\frac{\partial k_{j}}{\partial t_{j}} E-\left(1-K_{x_{j}} \omega_{-j}^{\prime}\right)=0 \text {. }
$$

This simplifies to

$$
\frac{\partial k_{j}}{\partial t_{j}}=\frac{\left(1-K_{x_{j}} \omega_{-j}^{\prime}\right)}{E}<0 .
$$

Equation (3.6) is the capital supply response to a one-unit increase in the capital tax. The response has negative sign: a higher capital tax yields a lower supply of mobile capital. 


\section{References}

Cumberland, J.H (1979), Interregional pollution spillovers and consistency of environmental policy, in Siebert, H (Ed), Regional Environmental Policy: The Economic Issues, NYU Press, NY, 255-81.

Fredrickson, P.G and D. Milliment (2002), Strategic interaction and the determination of environmental policy across US jurisdictions, Journal of Urban Economics, 51, 101-22.

Hanley, N, Shogren, J.F and B. White (2007), Environmental Economics in Theory and Practice, Second Edition, Palgrave/MacMillan, UK.

Hoel, M. and P. Shapiro (2003), Population Mobility and Transboundary Environmental Problems, Journal of Public Economics, 87: 1013-24.

Kunce, M. and J. Shogren (2002), On Environmental Federalism and Direct Emission Control, Journal of Urban Economics, 51: 238-45.

Kunce, M. and J. Shogren (2005), On interjurisdictional competition and environmental federalism, Journal of Environmental Economics and Management, 50, 212-24.

Kunce, M. and J. Shogren (2007), Destructive interjurisdictional competition: Firm, capital and labor mobility in a model of direct emission control, Ecological Economics, 60, 543-49.

Kunce, M. and J. Shogren (2008), Efficient decentralized fiscal and environmental policy: A dual purpose Henry George Tax, Ecological Economics, 65, 569-73.

Missfeldt, F., and J. Hauff (2004), The role of economic instruments, in Owen A.D and N. Hanley (Eds), The Economics of Climate Change, Routledge explorations in environmental economics, Oxford.

Petchey, J.D., and P. Shapiro (2002), Jurisdiction Tax and Policy Competition for Mobile Capital, The Economic Record, 78:241. 175-85.

Petchey, J.D., and S. Shapiro (2009), Equilibrium in fiscal competition games from the point of view of the dual, Regional Science and Urban Economics, 39, 97-108.

Stavins, R.N (1995), Transaction Costs and Tradable Permits, Journal of Environmental Economics and Management, 29, 133-48.

Stavins, R.N (2005), What Can We Learn from the Grand Policy Experiment? Lessons from $\mathrm{SO}_{2}$ Allowance Trading, in Stavins, R.N (Ed), Economics of the Environment: Selected Readings, Fifth Edition, W.W. Norton \& Company, New York.

Wellisch, D (1995), Locational choices of firms and decentralized environmental policy with various instruments, Journal of Urban Economics, 37, 290-310.

Wilson, J.D (1996), Capital mobility and environmental standards: Is there a theoretical basis for a race to the bottom? In Bhagwati, J., Hundee, R. (Eds), Fair Trade and Harmonization: Prerequisites for Free Trade, Vol. 1, MIT Press, Cambridge, MA, 393-427. 